\title{
A study on maternal factors affecting low birth weight in institutional deliveries
}

\author{
Chaithra A. ${ }^{1}$, Mahantappa A. Chiniwar ${ }^{2 *}$, Sharada B. Menasinkai ${ }^{3}$
}

\begin{abstract}
${ }^{1} 7$ th term UG student, AIMS and RH BG Nagara, Nagamangala, Mandya, Karnataka, India
${ }^{2}$ Department of Obstetrics and Gynecology, ${ }^{3}$ Department of Anatomy, Adichunchanagiri Institute of Medical Sciences and Research Center, BG Nagara, Nagamangala, Mandya, Karnataka, India
\end{abstract}

Received: 10 August 2020

Accepted: 10 September 2020

*Correspondence:

Dr. Mahantappa A. Chiniwar,

E-mail: drmachiniwar@gmail.com

Copyright: $\left({ }^{\circ}\right.$ the author(s), publisher and licensee Medip Academy. This is an open-access article distributed under the terms of the Creative Commons Attribution Non-Commercial License, which permits unrestricted non-commercial use, distribution, and reproduction in any medium, provided the original work is properly cited.

\section{ABSTRACT}

Background: Low birth weight is defined as birth weight below $2500 \mathrm{mg}$. WHO states prevalence of LBW is $26 \%$. LBW babies are more prone for neonatal morbidity and mortality. 1) To assess various factors like maternal age, height, education, socioeconomic status on the birth weight of the baby. 2) To assess obstetric factors like parity, gestational age, antenatal care, anemia, hypertension on the birth weight of the newborn.

Methods: A hospital bound cross sectional study done at the tertiary care centre. Study was done for a period of 2 months from 1st June to 30th July 2019 in Adichunchanagiri Institute of Medical Sciences and Research Hospital a rural medical college in Karnataka. Maternal data were collected and baby weight was recorded soon after birth on weighing scale.

Results: There were 65 births during the study period. There were 13 babies weighing less than $2500 \mathrm{gm}$. Prevalence of LBW was $20 \% .43 .47 \%$ mothers were aged between 18 to 25 years and $7.14 \%$ were more than 25 years. $30.4 \%$ mother's height was between 140 to $150 \mathrm{~cm}$ and $14.2 \%$ were more than $150 \mathrm{~cm}$. Regarding maternal education, $15.3 \%$ degree, $24.1 \%$ PUC, $15 \%$ High school and $33.3 \%$ were primary school level. Regarding socioeconomic status $22.2 \%$ low, $25 \%$ lower middle, $18.7 \%$ middle class, $18.7 \%$ belonged to upper middle class. Regarding gestational age $50 \%$ were $<37$ weeks, $15.5 \%$ between $37-42$ weeks, $10 \%$ were 42 weeks. $73.8 \%$ women had normal BP, $21.5 \%$ were prehypertensive, $4.6 \%$ had PIH.

Conclusions: Low birth weight is one of the important factors in infant morbidity and mortality. Maternal health was important factor in delivery of low birth babies. Maternal height, sex of baby, mode of delivery has no role in low birth weight babies.

Keywords: Anemia, Gestational age, Low birth weight

\section{INTRODUCTION}

Low birth weight (LBW) is defined by World Health Organization (WHO) as a birth weight less than $2500 \mathrm{~g} .{ }^{1}$ LBW can result from premature birth (before 37 weeks of gestation) or intrauterine-growth restriction (IUGR), or a combination of the two. ${ }^{2}$ The prevalence of low birth weight in India was found to be $26 \%$. There are numerous factors contributing to LBW, both maternal and foetal. ${ }^{3}$ Intrauterine growth and development is one of the most vulnerable process in human lifecycle and its aberration can result in lasting profound influence in later life. $^{4}$

The prevalence of LBW in any population reflects its Socio-economic development and status of public health. It is an indicator of future health and survival of child. ${ }^{5}$ The incidence of LBW varies widely between regions of the world with levels of $32 \%$ of southern Asia, 9\% in Eastern Asia, 11-16\% in Africa and 10-12\% in Latin America and Caribbean's. In India, 27\% babies are LBW and more than half of these are full term babies. LBW 
babies are 5-6 times more likely to die during perinatal period and 3 times more likely to die during infancy compared to normal birth weight babies. ${ }^{6}$

Studies suggest that short maternal stature, very young age, high parity, close birth spacing are associated factors. $^{7}$ In developed countries, predominant cause of LBW is preterm birth, whereas in developing countries, Intra uterine growth restriction (IUGR) is predominant cause of LBW. Mothers who had multiple gestations had higher risk of delivering LBW babies. The physical environment, specific and nonspecific infections, also plays an important role in determining the infant's birth weight and future health status. ${ }^{8}$ Extent of LBW is one of the key vital statistics used as an indicator of the quality of ANC, medical service, and general health service to mother. ${ }^{9}$

For the same gestational age, girls weighing less than boys, first born infants are lighter than subsequent infants, and twins weighing less than singletons.

Mothers in deprived socioeconomic condition frequently have LBW infants. In those setting, the infant's LBW stems primarily from the mother's poor nutrition and health over a long period of time, including during pregnancy, the high prevalence of specific and nonspecific infections, or from pregnancy complications underpinned by poverty. Physically demanding work during pregnancy also contributes to poor foetal growth. ${ }^{10}$ Our hospital is attached to rural medical college and few studies reported regarding the birth weight of the baby. Hence the present study was done to know the maternal factors affecting the birth weight.

The objective of the study was to assess the impact of various factors like maternal age, height, education, socioeconomic factors, parity, gestational age, antenatal care, anaemia, blood pressure on the birth weight of newborn. Hence the present study was done to know the maternal factors affecting the low birth weight babies.

\section{METHODS}

A cross-sectional hospital-bound study was conducted at a tertiary care centre. Study was done for a period of 2 months from $1^{\text {st }}$ June to $30^{\text {th }}$ July 2019. Sample size was total number of births during the study period. Inclusion criteria were all singleton normal babies born to both primiparous and multiparous women. Exclusion criteria were multiple births and babies with congenital anomalies and babies born to gestational diabetes mother. Digital weighing scale was used to weigh the babies.

Data was collected from the case sheet of mother and newborn record as well as by interacting with the mothers. Details of investigation reports during ante natal period such as blood group, $\mathrm{Hb} \%$ and ultrasound reports were collected. Data was collected in prescribed proforma with following details such as maternal age, height, literacy, socioeconomic status, gestational age, LMP, USG reports, mode of delivery, sex and weight of the baby. Statistical analysis was done using statistical package for social sciences software version 20 .

\section{RESULTS}

The results of the present study were analysed as follows, total number of births during study period were 65 . Number of babies who weighed less than 2500 gm were 13, which included 9 female and 4 male. Prevalence of LBW was $20 \%$. Out of 13 LBW babies 5 were delivered by lower segment caesarean section (LSCS) and 8 were normal deliveries.

Table 1: The percentage of $\mathrm{LBW}$ in relation to maternal age.

\begin{tabular}{|lllllll|}
\hline Maternal age & Babies wt<2500 gm & \% & Babies $\mathbf{w t}>\mathbf{2 5 0 0}$ gm & \% & Total & $\%$ \\
\hline $\mathbf{1 8 - 2 5}$ years & 10 & 43.47 & 13 & 56.52 & 23 & 100 \\
\hline $\mathbf{2 5}$ years & 3 & 7.14 & 39 & 92.8 & 42 & 100 \\
\hline Total & 13 & 20 & 52 & 80 & 65 & 100 \\
\hline
\end{tabular}

Table 2: Percentage of $\mathrm{LBW}$ in relation to maternal height.

\begin{tabular}{|c|c|c|c|c|c|c|}
\hline Height in $\mathrm{cm}$ & babies with wt $<2500$ gm & $\%$ & Babies with wt >2500 gm & $\%$ & Total & $\%$ \\
\hline $140-150 \mathrm{~cm}$ & 7 & 30.4 & 16 & 69.5 & 23 & 100 \\
\hline$>150 \mathrm{~cm}$ & 6 & 14.2 & 36 & 85.7 & 42 & 100 \\
\hline Total & 13 & 20 & 52 & 80 & 65 & 100 \\
\hline
\end{tabular}

Regarding $\mathrm{Hb} \%$ of mother among 23 anaemic mothers (<12 gm \%) 9 mothers had LBW babies and out of 42 mothers with $\mathrm{Hb} \%$ more than 12 gm \%, 4 mothers had
LBW babies. This shows that the incidence of LBW was common in both groups. 
In the present study 41 mothers $(63.1 \%)$ had normal systolic BP, 20 mothers $(30.8 \%)$ were pre-hypertensive and 4 mothers $(60.2 \%)$ had high systolic BP. And 48 out of 65 mothers had normal diastolic BP, 14 were prehypertensive and remaining 3 had very high diastolic BP.

Table 3: Percentage of $\mathrm{LBW}$ in relation to maternal education.

\begin{tabular}{|lllllll|} 
Maternal education & Baby wt $<\mathbf{2 5 0 0}$ gm & \% & Baby wt $>$ 2500 gm & \% & Total & $\%$ \\
\hline Primary & 1 & 33.3 & 2 & 66.6 & 3 & 100 \\
\hline High school & 3 & 15 & 17 & 85 & 20 & 100 \\
\hline PUC & 7 & 24.1 & 22 & 75.8 & 29 & 100 \\
\hline Degree & 2 & 15.3 & 11 & 84.6 & 13 & 100 \\
\hline Total & 13 & 20 & 52 & 80 & 65 & 100 \\
\hline
\end{tabular}

Table 4: Percentage of $\mathrm{LBW}$ in relation to maternal socioeconomic status.

\begin{tabular}{|c|c|c|c|c|c|c|}
\hline Income status & Baby wt <2500 gm & $\%$ & Baby wt >2500 gm & $\%$ & Total & $\%$ \\
\hline Lower class & 2 & 22.2 & 7 & 77.7 & 9 & 100 \\
\hline Lower middle class & 5 & 25 & 15 & 75 & 20 & 100 \\
\hline Middle class & 3 & 18.7 & 13 & 81.2 & 16 & 100 \\
\hline Upper middle class & 3 & 18.7 & 13 & 81.2 & 16 & 100 \\
\hline Upper class & 0 & 0 & 4 & 100 & 4 & 100 \\
\hline Total & 13 & 20 & 52 & 80 & 65 & 100 \\
\hline
\end{tabular}

Table 5: Correlation of gestational age and LBW.

\begin{tabular}{|c|c|c|c|c|c|c|}
\hline Gestational age in weeks & Baby wt <2500 gm & $\%$ & Baby wt >2500 gm & $\%$ & Total & $\%$ \\
\hline$<37$ weeks & 3 & 50 & 3 & 50 & 6 & 100 \\
\hline 37-42 weeks & 9 & 15.5 & 49 & 84.4 & 58 & 100 \\
\hline$>42$ weeks & 1 & 100 & 0 & 0 & 1 & 100 \\
\hline Total & 13 & 20 & 52 & 80 & 65 & 100 \\
\hline Gestational age in weeks & Baby wt $<2500$ gm & $\%$ & Baby wt >2500 gm & $\%$ & Total & $\%$ \\
\hline$<37$ weeks & 3 & 50 & 3 & 50 & 6 & 100 \\
\hline 37-42 weeks & 9 & 15.5 & 49 & 84.4 & 58 & 100 \\
\hline$>42$ weeks & 1 & 100 & 0 & 0 & 1 & 100 \\
\hline Total & 13 & 20 & 52 & 80 & 65 & 100 \\
\hline
\end{tabular}

\section{DISCUSSION}

The prevalence of Low Birth Weight (LBW) in the present study was $20 \%$ and is below the National average (27\%). In the present study there was no significant relation between maternal height and LBW of babies. 50 $\%$ of LBW babies were born to gestational age below 37 wks. $69 \%$ of LBW babies were born to anemic mothers.

Chandra S Metgud et al reported a community based study done in 2012 in rural Karnataka. ${ }^{4}$ There were 1131 mothers in the study group and 263 mothers had LBW babies giving the prevalence of $22.9 \%$.A study done in 2018 in North East Assam by Nirmal Gogoi among 300 mothers 78 had LBW babies $(26 \%){ }^{5}$

Radhakumari et al reported a study done during 2015 in King Gorge Hospital Vishakhpatnam in Andra Pradesh. ${ }^{6}$
Among 183 mothers delivered, 39 mothers had LBW babies (26\%). Anant Pawar et al reported a case control study done in 2017 in KMCT Medical College in rural Kerala. ${ }^{3}$ There were 60 cases and 124 controls, and the prevalence of LBW was $32.60 \%$.

Similar studies reported from different parts of Ethiopia giving different prevalence rates of LBW. Zelalem Abera et al reported a study from Southern Ethiopia in 2019 among the 358 mothers, the prevalence of LBW was $17.3 \%{ }^{1}$

BerhanuGizaw et al analysed a case control study from central Ethiopia, 94 cases and 376 controls and the prevalence of LBW was $20 \% .^{2}$ Meresa Gebremedhin et al reported in 2015, a hospital based cross sectional mixed study in Tigray, Northern Ethiopia and the prevalence of LBW was $14.6 \%$. $^{7}$ 
Table 6: Comparison of prevalence of LBW babies with other studies.

\begin{tabular}{|c|c|c|c|}
\hline Authors & $\begin{array}{l}\text { Sample } \\
\text { size }\end{array}$ & $\begin{array}{l}\text { No. of LBW } \\
\text { babies }\end{array}$ & $\%$ \\
\hline Abera et al $^{1}$ & 358 & 62 & 17.3 \\
\hline Gizaw et al $^{2}$ & 470 & 94 & 20 \\
\hline Pawar et al $^{3}$ & 184 & 60 & 32.6 \\
\hline Metgud et al $^{4}$ & 1131 & 260 & 22.9 \\
\hline Gogoi et al ${ }^{5}$ & 308 & 45 & 14.6 \\
\hline Radhakumari et al ${ }^{6}$ & 183 & 39 & 21.3 \\
\hline 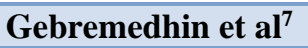 & 308 & 45 & 14.6 \\
\hline Present study & 65 & 13 & 20 \\
\hline
\end{tabular}

In the present study out of 13 cases 10 were born to mothers aged between 18-25 yrs and 3 babies to mothers aged $\geq 25$ yrs. According to study reported by Radha Kumari et al $21.4 \%$ of LBW babies were born to mothers age $\geq 20$ yrs and $20.8 \%$ were born to mothers aged $<20$ yrs. ${ }^{6}$ According to study reported by Chandra S Metgud et al $19.9 \%$ LBW babies were born to mothers aged between $20-24$ yrs, $33.3 \%$ to mothers aged between 30 - 34 yrs and $50 \%$ in mothers aged more than $35 \mathrm{yrs}^{4}$ According to NirmaliGogoi et al prevalence of LBW was $50 \%$ in age group less than $18 \mathrm{yrs}, 25 \%$ in mothers age between 18 to 34 yrs and $10 \%$ in more than 35 yrs age. ${ }^{5}$

In our study $10.7 \%$ LBW babies were born to mother's height between $140-150 \mathrm{~cm}$ and $9.30 \%$ were born to mother's height $\geq 150 \mathrm{~cm}$. According to study reported by Meresa Gebremedhin et $\mathrm{al}^{7} 28.6 \%$ LBW babies were born to mother's height $<150 \mathrm{~cm}$ and $13.2 \%$ in $\geq 150 \mathrm{~cm}$.

In the present study $92.3 \%$ mothers who gave birth to LBW babies completed secondary education. According to Meresa Gebremedhin et al 14 mothers were illiterates, 11 women done primary and 14 done secondary education. $^{7}$

Socioeconomic status is one of the important factor in LBW babies, in our study $84.62 \%$ were middle class. In study reported by Radhakumari et al $21.8 \%$ belonged to BPL and $18.75 \%$ belonged to APL. ${ }^{6}$ According to study reported by Anant Pawar et al annual income of mothers of LBW babies was $36,766 \pm 2.58$ and mothers of normal baby wt was $48,806 \pm 29.19 .{ }^{3}$ Acoording to Zelalem Abera et al among the $62 \mathrm{LBW}$ babies 35 were born to mothers belonging to middle and poor and 27 were born to higher socioeconomic status. ${ }^{1}$

Maternal nutrition is one of most important factor in LBW babies. In the present study 9LBW babies were born to mothers $\mathrm{Hb} \%$ less than 12 and $4 \mathrm{LBW}$ babies were born to mothers $\mathrm{Hb} \%$ more than 12 . According to to Zelalem Abera et al among the 62 LBW babies, 29 were born to mother's $\mathrm{Hb} \%$ less than $11 \mathrm{gm}$ and 33 babies to more than $11 \mathrm{gm}^{1}$ According to Radha Kumari et al $22.6 \%$ of LBW babies were born to mother's $\mathrm{Hb} \%$ less than $10 \mathrm{gm}$ and $6.6 \%$ to more than $10 \mathrm{gm} .{ }^{6}$ According to

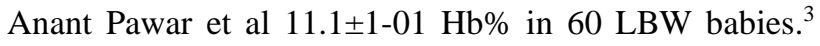
According to Nirmali Gogoi et al $\mathrm{Hb} \%$ of mother in cases and controls is same and overall $\mathrm{Hb} \%$ level in both group is low. ${ }^{5}$

In the present study out of 13 LBW babies 9 (13.84\%) were born at gestational age between $37-42$ wks and 3 (13.84\%) after 42 wks. According to study reported by Meresa Gebremedhin et al $71.4 \%$ were born $<37$ wks and $11.9 \%$ were born $\geq 37$ wks. $^{7}$

\section{CONCLUSION}

In the present study the prevalence of low birth weight babies was $20 \%$ and lower than the National average. Most of them belonged to low socioeconomic status. The significant predictors of LBW in our study was maternal education, socioeconomic status and haemoglobin $\%$. Improving the socioeconomic status of the mothers, expansion of utilization of ANC and strengthening the existing maternal services at the basic level of community is required.

\section{ACKNOWLEDGMENTS}

Authors would like to thank ICMR.

\section{Funding: ICMR}

Conflict of interest: None declared

Ethical approval: The study was approved by the Institutional Ethics Committee

\section{REFERENCES}

1. Abera Z, Ejara D, Gebremedhin S. "Nutritional and non-nutritional factors associated with low birth weight in Sawula Town, Gamo Gofa Zone, Southern Etiopia”. Abera et al. BMC Res Notes (2019)12:540.

2. Gizaw B, Gebremedhin S. "Factors associated with low birth weight in North Shewa zone, Central Ethiopia: case-control study." Gizaw and Gebremedhin Italian J Pediatr 2018;44:76.

3. Pawar A, Kumar D."Maternal factors associated with Low birth weight:a case control study in rural Kerala." International J Community medicine and public health 2017;4(10):3793-5.

4. Metgud CS, Naik VA Mallapur MD." Factors affecting birth weight of new born - A Community Based Study in Rural Karnataka, India”. PLOS $\backslash O N E$ 2012;7(7):e40040.

5. Gogoi N. "Maternal and neonatal risk factors of low birth weight in Guwahati Metro, Assam , Northeast India." The Academic Journal of Paediatrics and Neonatal 2018;6(5):001-6.

6. RadhaKumari P, BhavaniGuduri G, Venkateswarula. "A study on maternal factors affecting low birth weight in Institutional deliveries." IOSRJO Dental and Medical science 2015;14(1):45-8.

7. Gebremedhin M, Ambaw F, Admassu E, Berhane H. "Maternal associated factors of low birth weight:a 
hospital Based cross sectional mixed study in Tigray, Northern Ethiopia." BMC Pregnancy and Childbirth. 201515:222.

8. Talie A, Taddele M, Alemayehu M. "Magnitude of Low Birth Weight and Associated FactorsamongNewborns Delivered in Dangla Primary Hospital, Amhara regional state, Northwest Ethiopia, Hind J Pregn 2017:6.

9. Mulatu H, Zepre K, Betre M Hailemicael G. Magnitude and Factors Associated with Low Birth Weight among New Born in Selected Public Hospitals of Addis Ababa, Ethiopia. Glob J Med Res. 2016
10. Wardlaw T, Blanc A, Zupan J, Ahmam E. Low Birthweight Count, Regional And Global Estimates. www.who.int [UNICEF]; 2004.

Cite this article as: Chaithra A, Chiniwar MA, Menasinkai SB. A study on maternal factors affecting low birth weight in institutional deliveries. Int $\mathbf{J}$ Reprod Contracept Obstet Gynecol 2020;9:4245-9. 